\title{
FOOD SUPPLY CHAIN IN THE UNITED STATES: POTENTIAL ENVIRONMENTAL IMPACT
}

\author{
SHAHLA M. WUNDERLICH \& MARIELLE SMOLLER \\ Department of Nutrition and Food Studies, Montclair State University, USA
}

\begin{abstract}
The Food Supply Chain describes how raw materials are transferred from suppliers to manufacturers, distributers, retailers, and finally, to customers. Consumers are becoming increasingly concerned with how their food is sourced and produced in regard to the environment. The Green Food Supply Chain (GFSC) is gaining popularity in the United States (U.S.) as it integrates environmentally friendly and sustainable food production practices. Consumers are often unaware of the first step of the supply chain, which is food production. The different food production systems include Conventional, Organic, and Genetically Modified Organisms (GMO), and each has a different impact on the environment. In order to assess consumers' knowledge and preferences about their food's sources, 204 adult participants completed an online survey regarding this topic. The survey included demographic questions and general questions about their knowledge of and their beliefs regarding GMO food production and its impact on the environment. Almost half (48\%) of participants believed that GMO food production has a harmful impact on the environment, while $31.4 \%$ had no knowledge of GMO food production and environmental impact. A $\chi^{2}$ test showed a significant association between preference for non-GMO and individuals' beliefs on how GMO food production systems may impact the environment $\left(\chi^{2}(1)=\right.$ $29.592, p=0.001$ ). Of the 98 participants who believed that producing GMO foods has a harmful impact on the environment, $75 \%$ preferred foods to be labeled as non-GMO. Almost $80 \%$ of participants affirmed that the impact a particular food production method has on the environment affects their food purchasing decisions all of the time or sometimes. Individuals' beliefs and knowledge of food production systems, and their possible impact on the environment, are important and influence demand. Therefore, consumers should be provided with more education and information about their food's sources.

Keywords: environment, consumer, Genetically Modified Organism (GMO), systems, Food Supply Chain (FSC), Green Food Supply Chain (GFSC), sustainability, education, purchasing decisions, labelling.
\end{abstract}

\section{INTRODUCTION}

The Food Supply Chain refers to the processes that include delivery of food from farms to consumers. During this process, raw materials (food) are moved from suppliers, to manufacturers, distributers, retailers, and finally, to customers. All of these entities are interconnected and influence one another as products move down the supply chain [1]. For example, a farmer (the supplier) may harvest corn and sell his product to a company that manufactures High Fructose Corn Syrup (HFCS), which is used in many food products. The manufacturers subsequently distribute their products to the retail locations that will eventually sell the good directly to the consumer. The concern for environmental protection, food accessibility, and food security is becoming increasingly important as the world's population expands. Therefore, food production systems are moving more toward more sustainable processes that produce higher product yields. On the other hand, consumers are becoming concerned with how different food production systems impact the environment as they move through the supply chain.

Therefore, the Green Food Supply Chain (GFSC) is gaining popularity in the US as it emphasizes environmentally friendly and sustainable practices. It is a concept that takes the environmental impact of the Food Supply Chain into consideration. For example, "green" 
food companies strive to minimize pollution produced during all phases of the supply chain, including food production, transportation, and delivery to consumers. Performing Life Cycle Assessments on crops to predict sustainability and delivering quality goods to consumers are both goals of the GFSC [2]. The consumer facet of the Food Supply Chain includes consumer demand and preference for certain products. Many factors influence consumers' food selection, ranging from taste, to nutrition, to cost. Most recently, consumers are becoming increasingly more concerned and interested in how their food is sourced and produced as GMO food production expands [3]. Based on conflicting messages from the media, some consumers fear that GMO's are not safe for consumption, are unethical, and that their production is harmful to the environment.

\subsection{The green food supply chain}

The food supply chain is a dynamic supply and demand network of organizations, people, activities, information, and resources involved in moving food products from suppliers to consumers. The key players within the Food Supply Chain include suppliers, distributers, manufacturers, retailers, and consumers. The Green Food Supply Chain (GFSC) emerged as Food Supply Chain participants began incorporating environmentally sustainable practices into production. Some examples of environmentally conscious processing practices include reducing the amount of pesticides used during farming in order to promote biodiversity, decreasing water usage, preventing soil erosion, and treating livestock ethically [4]. There are companies that are using GFSC with success and innovation. For example, one company replenishes water in water-insecure communities in order to offset the 305 billion litres of water used per year in the production of its products [5]. During the transportation process, some companies may also opt to condense shipments to reduce $\mathrm{CO}_{2}$ emissions while shipping products. From a retailing standpoint, using recyclable packaging for products would be a sustainable way to participate in the Food Supply Chain [4]. Finally, consumers may participate within the GFSC by choosing products that have been produced in environmentally conscious ways. It is important for consumers to do their own research so that they are knowledgeable about how their food was processed within the Food Supply Chain.

As the world population grows, entities participating within the Food Supply Chain strive to balance the need for increased food production with sustainable practices [4]. According to the Food and Agricultural Organization (FAO), if global food production does not expand by at least $60 \%$ within the next thirty years, then the world may face a global food shortage [4]. It has become necessary for all the players within the Food Supply Chain to collaborate together in order to produce products that satisfy these ever-changing needs [4]. This pull to satisfy globalized food production has ultimately lead to the increased production of GMOs.

\subsection{Food production methods}

The three main food systems include GMO, Organic, and Conventional. This study focuses on GMOs within the Food Supply Chain and how consumers react to their labels. Genetically Modified Organisms (GMOs) refer to food products whose genes have been altered with biotechnology in order to express certain favourable characteristics. Scientists introduce genetic sequences into organisms in order to enhance farming techniques and to produce more attractive products with better yields. Many GM foods are bred to be resistant to pests and disease, to be more tolerable of pesticides, to improve nutritional value, and to prolong shelf life [6]. Scientists began manipulating genes and genetically modifying crops in the 
1980's, and the first GM crop became available to the public in 1994 [7]. For the first time, the public was exposed to a GM tomato whose genetic sequence was altered to prolong and enhance its ripeness. GM foods eventually became commercially popular in the American food supply by 2006; however, there were no specific labeling policies or rules in effect at the time. By 2013, the United States became the world's largest producer of GM crops, with over $94 \%$ of its soybeans and $90 \%$ of its corn undergoing genetic modification [7]. Although GM food production has become widely utilized, there is some debate regarding its safety and about its impact on the environment. For this reason, consumers began demanding that food manufacturers disclose GM ingredients on their packaging. Currently, the FDA allows manufacturers to voluntarily choose whether or not they wish to disclose if their products contain GM ingredients. The only entity in the United States that currently labels non-GMO foods is the Non-GMO Project, which began labeling foods in 2010 [8]. The non-GMO Project is a non-profit organization that verifies that a product contains less than $0.9 \%$ of GMO ingredients with a "Non-GMO Verified" label. The voluntary declaration of GM ingredients is about to change after a new national GMO-labeling law was signed in July 2016 [9]. This new law mandates that all GM foods must disclose their GM ingredients to consumers. GM ingredients will be disclosed via an electronic code, text, or symbol that will be displayed on food packages. More specific rules and standards regarding this law will be set by the United States Department of Agriculture (USDA) within the next two years [9].

According to the USDA, organic foods must meet the following requirements: 1) must be produced without the use of genetic engineering, ionizing radiation, or sewage sludge; 2) must be produced with only substances from a list of approved Allowed Substances; and 3) production must be overseen by a USDA National Organic Program-authorized certifying agent while following all of USDA's regulations [10]. Foods produced through non-organic methods, also known as conventional foods, often contain GMOs. Conventional farming is the oldest and most traditional production method. However, modern technology has created significant crossover between conventional and GM production [11].

\subsection{Consumer knowledge and attitudes toward GMOs}

According to the literature, consumer attitudes toward GM foods are highly dependent on their personal morals and ethics, and how society views and portrays these foods to the consumer. Other factors affecting the acceptability of GM foods include how "natural" or "unnatural" a product is, perceived safety, environmental impact, attitude toward technology, policies, education and income level, and price [3]. Consumers' overall concern for the world appears to be linked to sustainable and organic food production methods that work to preserve the world's environment while yielding high food production. A study from the Journal of Law, Medicine, \& Ethics examined the extent to which consumers associate health, safety, and the environment with certain food labels [12]. The study asked 185 participants from the California Western School of Law community to rate how healthy, safe, or environmentally friendly GMO foods are compared to other food products. On average, participants consistently rated GMO foods 1.1-1.8 points lower on a five-point scale than organic or nonGMO foods. The study ultimately revealed that participants favoured food labels that appear more natural over foods containing GM ingredients, despite the fact that the FDA does not promote the idea that GMOs are not safe for consumption [12].

A study from the University of Latvia assessed 1,184 participants' knowledge, attitudes, and beliefs toward GMOs using a ten-point Likert scale [13]. The study revealed that consumers were very sceptical of GM animal products, with an average acceptance of 1.97. Participants evaluated the benefits of GMOs as low (average value of 3 or less) but expressed 
that they would be more accepting of GMOs if they were more environmentally friendly. Participants also expressed concern over GMOs' safety, with the majority of participants believing that GMOs are not safe for the environment, for animals, or for humans. Participants also agreed (average 6.89) that GMOs are simply unnatural, something they view negatively. Despite the participants' strong, negative perceptions of GMOs, half of the participants rated their knowledge of GMOs less than a five, while $16.4 \%$ of participants ranked their knowledge at a 3 [13]. A study that surveyed 346 nursing students' attitudes toward GMOs revealed that $77.7 \%$ believed GMOs are dangerous to living things, and $72.8 \%$ thought that GMOs are not safe for consumption [14]. However, 82.9\% strongly believed that society is not well-informed regarding the risks and benefits of GMOs [14].

A study from Rutgers University in New Jersey also confirms that there is a lack of knowledge surrounding the word "non-GMO." More than half (54\%) of the 491 participants who completed an online survey assessing their knowledge, attitudes, and beliefs regarding GM foods admitted to knowing little to nothing about GM foods, while $25 \%$ stated that they have never heard of GMOs. Despite this lack of awareness, $73 \%$ of respondents believed that the labeling of GM foods should be mandatory, and only $8 \%$ thought that GM foods were safe to eat [7]. However, according to a study that surveyed 331 people in northern New Jersey about their knowledge and attitudes toward GM food production, attitudes toward GMs were strongly correlated with overall knowledge $(\mathrm{r}=0.701)$. This study revealed that the stronger a consumer's knowledge about GM food production was, the more positively they viewed non-GM foods $(r=0.413)$ [3]. These studies suggest that consumers have negative perceptions regarding GMOs due to a gap in knowledge.

The public opinion about GM foods is highly polarized due to receiving conflicting messages from multiple sources of information. The misconceptions surrounding GMOs is likely due to consumers not knowing where to look for reliable information, and due to the fact that information regarding GM foods is still evolving [3]. A study from the Journal of Review of Policy Research conducted focus groups to better understand consumer attitudes toward the use of nanotechnology in food production [15]. Seven ninety-minute focus groups conducted in Minnesota and North Carolina evaluated fifty-six participants' knowledge, attitudes, and beliefs toward "nano-foods". Analysis of the focus groups revealed a general consensus that foods produced with nanotechnology should be labeled appropriately. However, participants voiced concerns that if foods possessed a label indicating a food was made with nanotechnology, consumers may not know what that necessarily means: "Putting that (label) 'made with nanotechnology' isn't going to mean anything to anyone, unless they know what nanotechnology is" [15]. This study shows that there is a great deal of uncertainty regarding the knowledge of GM foods and foods produced with technology. A systematic review asserts that consumer knowledge of GMOs is generally low, which leads to misconceptions about their health and safety. The authors attribute this gap in knowledge to the fact that consumers typically get their information about GMOs from incomplete sources such as the media and the Internet [16]. The study that assessed Latvian nursing students' attitudes toward GMOs revealed that $21.7 \%$ of participants get their information about GMOs from the internet, $74.3 \%$ from the television or radio, $27.7 \%$ from the newspaper, and $22.3 \%$ from a friend [14]. The ultimate consensus that may be made is that despite a lack of consumer knowledge regarding the term GMO, consumers tend to have negative attitudes and perceptions toward GM products. 


\subsection{GMO impact on the environment}

The impact that GMOs have on the environment is controversial, as the pros and cons of GMO food production are not completely understood. The environmental impact of GMO production is ambiguous, as there is currently no consensus on what is considered "environmental damage" in regard to GMO food production [17]. There is currently a delicate balance between feeding the growing world population while producing food in environmentally conscious ways. Research shows that GMO crops are resistant to pests and disease, allowing for more efficient production and abundant crop yields. This efficient production utilizes less land and resources, minimizing these aspects of potential environmental impact [18]. In contrast, organic food production causes less environmental damage per square mile cultivated. However, organic farming may have a negative overall impact on the environment as it utilizes more land and resources during production [19]. Opponents to GMOs argue that GMO production compromises biodiversity as GM crops transmit traits to native species. This ultimately leads to a decline in genetic diversity, something that is crucial to the survival of certain wild variety crops [18]. A recent review of the environmental impact of GMOs asserts that there is insufficient evidence to explicitly classify GMOs as either strictly harmful or beneficial to the environment. The review addresses both the issues and advantages of GMO production, while acknowledging that further research in this area is needed [20]. Quantifying the environmental safety of GM food production is challenging due to this ambiguity. Assessing the environmental impact of GM crops ultimately requires further research and longitudinal studies by scientists and farmers.

This paper will focus on the food production and consumer pieces of the Food Supply Chain. Furthermore, this paper will relate these aspects of the Food Supply Chain back to the environment. The purpose of this study is to assess consumer knowledge, attitudes, and beliefs regarding GMO food production in relation to its impact on the environment.

\section{MATERIALS AND METHODS}

Online surveys were administered using an online plea to the Montclair State University community in Montclair, New Jersey, USA. Eligible participants needed to be 18 years or older, live in the United States, and routinely purchase foods in supermarkets of the United States. The 15-min survey assessed knowledge and perception of genetically modified foods and organic foods. The institutional review board (IRB) approved the protocol for the study.

Participants were first asked whether or not they have heard of the term non-GMO before, and were then prompted to provide their own definition of the term. Subsequent questions included prompts about their purchasing behaviors and beliefs regarding these products. Participants were asked how often they notice and look for non-GMO food labels in the grocery store (all the time, sometimes, or never), and if they prefer to purchase products with a non-GMO label (yes or no). Participants were then asked, "the following statement BEST reflects my beliefs regarding the impact of producing GMO foods on the environment". Participants were able to choose from the following options: A) I believe that producing GMO foods has a harmful effect on the environment, B) I believe that producing GMO foods has a beneficial effect on the environment, $\mathrm{C}$ ) I believe that producing GMO foods has no effect on the environment, or D) I do not know how producing GMO foods affects the environment. Demographic questions regarding age, ethnicity, gender, income, education level, and location were also included to elicit more context and qualitative data.

The Statistical Package for the Social Sciences (SPSS) 22.0 (Armonk, NY: IBM Corp) and Microsoft Excel were used to analyze the data. Chi Square Tests were used to assess the 
association between preference for non-GMO labels and one's beliefs regarding how GMO production impacts the environment.

\section{RESULTS}

The original sample size was 214 individuals were a part of the original sample size. The final sample size was 204, as 10 participants were eliminated from the study due to incomplete survey responses. The participants were mostly female $(83.7 \%)$ and white $(72.5 \%)$, with ages ranging from $18-64$ years of age (mean $=25.9)$. More than half $(54.4 \%)$ of participants earn $\$ 50,000$ /year or less, and $78.9 \%$ of participants hold a bachelor's degree or lower. The majority $(92.2 \%)$ of participants resided in New Jersey, while the rest were from Pennsylvania, Delaware, Virginia, New York, and Georgia.

Table 1: Demographics $(n=204)$.

\begin{tabular}{|c|c|c|}
\hline Category & $n$ & $\%$ \\
\hline \multicolumn{3}{|l|}{ Gender } \\
\hline Male & 33 & $16.2 \%$ \\
\hline Female & 170 & $83.7 \%$ \\
\hline No response & 1 & $0.5 \%$ \\
\hline \multicolumn{3}{|l|}{ Age (Years) } \\
\hline Mean $( \pm$ SD $)$ & & $25.9( \pm 8.4)$ \\
\hline Range & & $46(18-64)$ \\
\hline \multicolumn{3}{|l|}{ Ethnicity (may identify as multiple) } \\
\hline White, non-Hispanic & 148 & $72.5 \%$ \\
\hline Asian & 13 & $6.4 \%$ \\
\hline Hispanic or Latino & 35 & $17.2 \%$ \\
\hline Black of African-American, non-Hispanic & 10 & $4.9 \%$ \\
\hline Other & 2 & $1.0 \%$ \\
\hline No response & 1 & $0.5 \%$ \\
\hline \multicolumn{3}{|l|}{ Income } \\
\hline$\$ 0-\$ 25,000$ & 48 & $23.5 \%$ \\
\hline$\$ 25,001-\$ 50,000$ & 35 & $17.2 \%$ \\
\hline$\$ 50,001-\$ 75,000$ & 28 & $13.7 \%$ \\
\hline$\$ 75,001-\$ 100,000$ & 24 & $11.8 \%$ \\
\hline$\$ 100,001+$ & 34 & $16.7 \%$ \\
\hline No response & 35 & $17.2 \%$ \\
\hline \multicolumn{3}{|l|}{ Education } \\
\hline High school diploma & 49 & $24.0 \%$ \\
\hline Associate degree & 25 & $12.3 \%$ \\
\hline Bachelor's degree & 87 & $42.6 \%$ \\
\hline Master's degree & 37 & $18.1 \%$ \\
\hline Doctoral degree & 3 & $1.5 \%$ \\
\hline No response & 3 & $1.5 \%$ \\
\hline
\end{tabular}


Table 2: Awareness of production methods $(n=204)$.

\begin{tabular}{|l|c|c|c|}
\hline \multicolumn{4}{|c|}{ Awareness of production methods } \\
\hline I have heard of the term... & Yes & No & No response \\
\hline $\begin{array}{l}\text { "Genetically Modified } \\
\text { Food" (GMO) }\end{array}$ & $201(98.5 \%)$ & $3(1.5 \%)$ & $0(0.00 \%)$ \\
\hline & I do not know & $\begin{array}{c}\text { Able to } \\
\text { provide } \\
\text { explanation }\end{array}$ & No response \\
\hline $\begin{array}{l}\text { Explanation of what GMO } \\
\text { means }\end{array}$ & $16(7.8 \%)$ & $186(91.2 \%)$ & $2(1.0 \%)$ \\
\hline
\end{tabular}

Table 2 represents awareness of production methods. $98.5 \%$ of participants had heard of the term "GMO," while $7.8 \%$ of the sample admitted to not knowing what the term means.

About half (48\%) of the participants believed that GMO food production has a harmful impact on the environment, while $31.4 \%$ did not know how GMO food production affects the environment (see Table 3). A chi square test showed a statistically significant association between preference for non-GMO labels and an individuals' beliefs on how producing GMOs impacts the environment $\left(\mathrm{X}^{2}(1)=29.592, p=0.001\right)$. Of the 98 participants that believed that producing GMO foods has a harmful impact on the environment, $75 \%$ preferred foods with a non-GMO label to foods without a non-GMO label. Of the 64 participants who stated that they did not know how GMO food production impacts the environment, $51 \%$ do not prefer food items with a non-GMO label. The majority of participants (79.4\%) stated that the impact a particular food had on the environment affects their food purchasing decisions all of the time or sometimes (see Table 4).

Table 3: Environmental beliefs for non-GMO foods $(n=204)$.

\begin{tabular}{|l|c|c|}
\hline \multicolumn{1}{|c|}{ Statement } & $n$ & $\%$ \\
\hline $\begin{array}{l}\text { The following statement best reflects my beliefs regarding } \\
\text { the impact of producing GMO foods on the environment: }\end{array}$ & & \\
\hline $\begin{array}{l}\text { I believe that producing GMO foods has a harmful effect on } \\
\text { the environment }\end{array}$ & 98 & $48.0 \%$ \\
\hline $\begin{array}{l}\text { I believe that producing GMO foods has a beneficial effect } \\
\text { on the environment }\end{array}$ & 17 & $8.3 \%$ \\
\hline $\begin{array}{l}\text { I believe that producing GMO foods has no effect on the } \\
\text { environment }\end{array}$ & 7 & $3.4 \%$ \\
\hline $\begin{array}{l}\text { I do not know how producing GMO foods affects the } \\
\text { environment }\end{array}$ & 64 & $31.4 \%$ \\
\hline No answer & 18 & $8.8 \%$ \\
\hline
\end{tabular}


Table 4: Environment and impact on purchasing decisions $(n=204)$.

\begin{tabular}{|l|c|c|c|c|}
\hline Statement & $\begin{array}{c}\text { All of the } \\
\text { time }\end{array}$ & Sometimes & Never & Missing \\
\hline $\begin{array}{l}\text { The impact of producing a } \\
\text { certain food item on the } \\
\text { environment affects my food } \\
\text { purchasing decisions }\end{array}$ & $24(11.8 \%)$ & $138(67.6 \%)$ & $24(11.8 \%)$ & $18(8.8 \%)$ \\
\hline $\begin{array}{l}\text { My belief about how } \\
\text { producing GMO foods } \\
\text { impacts the environment } \\
\text { influences my food } \\
\text { purchasing decisions }\end{array}$ & $32(15.7 \%)$ & $86(42.2 \%)$ & $57(27.9 \%)$ & $29(14.2 \%)$ \\
\hline
\end{tabular}

\section{DISCUSSION}

The results of this study ultimately reveal that despite the ambiguity surrounding GMOs and the impact that their production has on the environment, consumers perceive them as harmful to the environment. The majority of participants either does not know how GMO food production impacts the environment $(31.4 \%)$ or believe that it does have a harmful effect on the environment $(48.0 \%)$. There is clearly some familiarity with the term GMO and GMO labels among participants, as nearly all (98.5\%) have heard of the term before. The results also suggest that consumers are being exposed to more GMO labels, as $85.3 \%$ of participants state that they see these labels in supermarkets in the United States. Furthermore, $79.4 \%$ of these participants state that their beliefs regarding GMOs and the environment affect their purchasing decisions at least all of the time or sometimes. It should also be noted that the participants who have negative attitudes toward GMOs and their environmental impact tend to be proponents of GMO labeling policies. The data is consistent with previous literature that asserts that consumers tend to have negative attitudes toward GMO food production and the environment. As previously discussed, consumers have a low acceptance level regarding GMOs regarding their safety and impact on the environment [13]. However, data from this study conflicts with previous studies that show that there is a lack of awareness surrounding the term GMO among consumers. The majority (98.5\%) of participants within this study have heard of the term "GMO". Conversely, the Rutgers University study dealt with a population very unfamiliar with the term GMO, with approximately $54 \%$ of participants admitting to knowing little to nothing about the term [7].

The results and the literature suggest that beliefs regarding how GM food production impacts the environment have the potential to influence purchasing behaviors and preference for labels. An increased consumer demand for GMO labels has the power to impact labeling policies, and even the types of foods that food companies decide to produce. The powerful influence of consumers' beliefs highlights the importance of relaying accurate information about GMOs to the public. The findings pose the question of where are consumers getting the idea that certain products are more desirable, valuable, safer, or environmentally-friendly than others? It is evident that non-GMO labels have a powerful impact not only on consumers' attitudes and beliefs, but also on their purchasing decisions as well. A systematic review from the American Journal of Agricultural Economics discusses the confusion surrounding the new abundance of information available to consumers via labels. The review attributes consumers' difficulty understanding labels to three things: 1) messages on labels are often complex; 2) there are a variety of labels on the market that have similar meanings; and 3 ) the risks and benefits of certain labels are misrepresented and therefore misinterpreted. 
Certain products are being portrayed as superior due to their labels, yet consumers cannot determine whether or not this desirability is actually of any value [21]. When consumers do not fully understand the meaning of certain labels, information may bombard them and make it even more challenging for them to comprehend the validity of certain claims. This suggests that consumers may not be freely or accurately exercising their beliefs when purchasing nonGMO products, since they may not be able to fully understand their labels.

\section{CONCLUSION}

The main conclusion to be drawn from this study is that despite the lack of general knowledge available regarding the impact that GMOs have on the environment, consumers have strong opinions about how food production systems impact the environment. There is therefore a need for more consumer education regarding the safety of GM food production in regards to the environment. If consumers were more knowledgeable about the risks and benefits surrounding purchasing foods with GM-containing ingredients, then they would be able to develop more educated opinions and attitudes about them. More consumer education would allow consumers to decipher labels more accurately and make purchasing decisions that accurately reflect their beliefs. Future research regarding the risks and benefits of GMO food production is also needed so that credible and reliable information may be conveyed to consumers. This would ultimately allow consumers to freely exercise their beliefs while making informed decisions. The growing popularity of non-GMO products is expected to drive growth of organic food around the globe to $\$ 320$ billion by 2025 as people become more aware of the environmental impact of other food production systems [22]. This rapid growth places further emphasis on the need to increase knowledge and awareness of the impact that GM food production has on the environment.

The main limitation of this study is that the sample population was small, largely white, female, and from northern New Jersey. Therefore, the results cannot be generalized to the entire United States population. Further research in this area using a more diverse population using a larger sample size would provide more insight to this issue. There is also the risk of survey bias within this study, as participants may have responded in ways that make their purchasing decisions appear more altruistic than they actually are.

\section{VITAE}

Shahla Wunderlich is a Professor Nutrition and Food Science at Montclair State University. She studies the full spectrum of nutritional needs - for mothers and children and older adults. Her scholarly interests include nutrition assessments, global food studies and most recently, food production systems and their environmental impact. She served as an editor and reviewer of nutrition textbooks. Dr. Wunderlich received her Ph.D. from the Massachusetts Institute of Technology (MIT) in Nutritional Biochemistry and Metabolism. She is a Registered Dietitian (RD) and Certified Nutrition Specialist. She has received many awards, including the Outstanding Dietetic Educator Award and the Montclair State University Outstanding Faculty Award.

Marielle Smoller is a Nutrition and Food Science graduate student at Montclair State University. She is also a Registered Dietitian (RD), and completed both her undergraduate coursework and Dietetic Internship at the University of Delaware. She has experience in weight management counseling in the outpatient setting. As a graduate assistant at Montclair, Marielle collaborates with the faculty members in the Department of Nutrition and Food Studies on variety of research studies such as research on consumer knowledge and attitudes toward GMO products. 


\section{ACKNOWLEDGEMENT}

The authors would like to thank Dr. Mizuho Sato and Professor Masaru Nakano of Keio University in Japan for introducing and inspiring the study of the Food Supply Chain.

\section{REFERENCES}

[1] Meant4Teachers, Lesson 4: What is the Food Supply Chain? http://meant4teachers.com/wpcontent/uploads/2014/02/What-is-the-Food-SupplyChain.pdf. Accessed on: 16 Nov. 2016.

[2] Govindan, K., Sustainable consumption and production in the food supply chain: A conceptual framework. International Journal of Production Economics, 2017. DOI: 10.1016/j.ijpe.2017.03.003.

[3] Vecchione, M., Feldman, C. \& Wunderlich, S., Consumer knowledge and attitudes about genetically modified food products and labelling policy. International Journal of Food Sciences \& Nutrition, 66(3), pp. 329-335, 2015.

[4] León-Bravo, V., Caniato, F., Caridi, M. \& Johnsen, T., Collaboration for sustainability in the food supply chain: A multi-stage study in Italy. Sustainability, 9(7), p. 1253, 2017. DOI: $10.3390 / \mathrm{su} 9071253$.

[5] Coca-Cola India Pvt. Ltd., Coca-Cola India Sustainability Report 2014. https://prodwp.pub.coke.com/wpcontent/uploads/sites/62/2016/01/SustainabilityReport-Coca-Cola-India.pdf.

[6] US Department of Agriculture, Biotechnology FAQs. www.usda.gov/topics/ biotechnology/biotechnologyfrequently-asked-questions-faqs. Accessed on: 16 Nov. 2017.

[7] Hallman, W.K., Cuite, C.L. \& Morin, X.K., Public perceptions of labeling genetically modified foods. Working Paper No. 2013-1. http://humeco.rutgers.edu/ documents_PDF/news/GMlabelingperceptions.pdf. Accessed on: 16 Nov. 2017.

[8] The Non-GMO Project, Product Verification. www.nongmoproject.org/productverification/. Accessed on: 16 Nov. 2017.

[9] ABC News Internet Ventures, Obama signs Bill mandating GMO Labeling, 29 Jul. 2016. http://abcnews.go.com/US/obama-signs-bill-mandating-gmolabeling/story?id= 41004057. Accessed on: 16 Nov. 2017.

[10] US Department of Agriculture, Organic Labeling, 2016. www.ams.usda.gov/ rulesregulations/organic/labelling. Accessed on: 16 Nov. 2017.

[11] US Department of Agriculture, USDA Coexistence Factsheet: Conventional Farming. www.usda.gov/sites/default/files/documents/coexistence-conventionalfarmingfactsheet.pdf. Accessed on: 16 Nov. 2017.

[12] Sax, J. \& Doran, N., Food labeling and consumer associations with health, safety, and environment. Journal of Law, Medicine \& Ethics, 44(4), pp. 630-638, 2016. DOI: $10.1177 / 1073110516684805$.

[13] Aleksejeva, I., An empirical study of Latvian consumers' attitudes and perceptions towards genetically modified organisms. European Integration Studies, 10, pp. 157$168,2016$.

[14] Turker, T. et al., Determination of knowledge, attitude, behavior about genetically modified organisms in nursing school students. Gulhane Medical Journal, 55(4), pp. 297-304. DOI: 10.5455/gulhane.33326.

[15] Brown, J. \& Kuzma, J., Hungry for information: public attitudes toward food nanotechnology and labeling. Review of Policy Research, 5, p. 512, 2013. DOI: 10.1111/ropr.12035. 
[16] Wunderlich, S. \& Gatto, K.A., Consumer perception of genetically modified organisms and sources of information. Advances in Nutrition, 6(6), pp. 842-851, 2015. DOI: 10.3945/an.115.008870.

[17] National Academies of Sciences, Engineering, and Medicine, Genetically Engineered Crops: Experiences and Prospects, The National Academies Press: Washington, DC, 606 pp., 2016. DOI: 10.17226/23395.

[18] Wunderlich, S., Gatto, K. \& Smoller, M., Consumer knowledge about food production systems and their purchasing behavior. Environment, Development, and Sustainability, pp. 1-11, 2016. https://doi.org/10.1007/s10668-017-0021-y.

[19] Meier, M., Stoessel, F., Jungbluth, N., Juraske, R., Schader, C. \& Stolze, M., Review: Environmental impacts of organic and conventional agricultural products - Are the differences captured by life cycle assessment? Journal of Environmental Management, pp. 149193-149208, 2015. DOI: 10.1016/j.jenvman.2014.10.006.

[20] Tsatsakis, A. et al., Environmental impacts of genetically modified plants: A review. Environmental Research, pp. 156818-156833, 2017.

DOI: 10.1016/j.envres.2017.03.011.

[21] Bonroy, O. \& Constantatos, C., On the economics of labels: how their introduction affects the functioning of markets and the welfare of all participants. American Journal of Agricultural Economics, 97(1), pp. 239-259, 2015. DOI: 10.1093/ajae/aau088.

[22] New Hope Network, Prediction: Organic foods and beverages market to reach $\$ 320$ billion by 2025 . www.newhope.com/news/prediction-organic-foods and beveragesmarket-reach-320-billion-2025. 